\title{
Plasma and urinary phyto-oestrogens as biomarkers of intake: validation by duplicate diet analysis
}

\author{
Margaret R. Ritchie ${ }^{1 *}$, Michael S. Morton ${ }^{2}$, Nigel Deighton ${ }^{3}$, Alison Blake \\ and John H. Cummings ${ }^{4}$ \\ ${ }^{1}$ Bute Medical School, University of St Andrews, St Andrews, Fife, Scotland, UK \\ ${ }^{2}$ Department of Medical Biochemistry, University of Wales College of Medicine, Cardiff, Wales, UK \\ ${ }^{3}$ Scottish Crop Research Institute, Invergowrie, Dundee, Scotland, UK \\ ${ }^{4}$ Department of Molecular and Cellular Pathology, University of Dundee, Ninewells Hospital and Medical School, \\ Dundee, Scotland, UK
}

(Received 27 July 2003 - Revised 6 November 2003 - Accepted 6 November 2003)

\begin{abstract}
Estimating intake of phyto-oestrogens (PO) is difficult because there is inadequate information on the PO content of foods. Development of a biomarker of intake is therefore necessary for carrying out epidemiological studies. We aimed to validate a newly constructed PO database, containing more than 600 values assigned to foods by using duplicate diet analysis, and to investigate the relationships between measured PO intake, urinary excretion and plasma concentrations of PO. Fourteen subjects with estimated dietary intakes of PO ranging from 0 to $44 \mathrm{mg} / \mathrm{d}$, measured by $7 \mathrm{~d}$ weighed intake, completed a duplicate diet collection over $24 \mathrm{~h}$. Concurrently, a $24 \mathrm{~h}$ urine collection, validated using $p$-aminobenzoic acid, was obtained and one timed spot plasma sample taken. Duplicate diets, complete urine collections and plasma samples were analysed for total genistein and daidzein using liquid chromatography-MS to determine PO intake. The potential for $24 \mathrm{~h}$ urinary excretion and plasma PO concentrations to reflect dietary intake was investigated. Mean estimated and measured dietary PO intakes were 12.3 and $11.0 \mathrm{mg} / \mathrm{d}$ respectively. The correlation between estimated intake and measured intake of PO was highly significant $(r 0.98, P<0.001)$. Urinary excretion $(24 \mathrm{~h})$ and plasma concentrations of PO were significantly related to measured dietary PO intake (r $0.97, P<0.001$ and $r 0.92, P<0.001$ respectively). The relationship between $24 \mathrm{~h}$ urinary PO excretion and timed plasma concentrations was also significant $(r 0.99, P<0.001)$. These findings validate the $\mathrm{PO}$ database and indicate that $24 \mathrm{~h}$ urinary excretion and timed plasma concentrations can be used as biomarkers of PO intake.
\end{abstract}

Biomarker: Phyto-oestrogen database: Dietary intake: Plasma: Urine

Phyto-oestrogens (PO) are currently of great interest because of their potential anti-cancer and antioxidant properties. The assessment of dietary intake of PO is limited by the paucity of quantitative data on the content of many individual foods, combined dishes and composite diets. There is therefore a need for an independent biomarker of PO intake for epidemiological studies. Such a biomarker needs to be easy to measure and to reflect dietary intake accurately over a wide range of consumption levels (Wild et al. 2001).

The principal PO in foods are the isoflavones genistein and daidzein. We have developed a new database of total genistein + daidzein values for more than 600 UK foods; it is designed to be capable of reflecting dietary intake more accurately then previous methods (Jones et al. 1989). The accuracy of the database and hence its ability to reflect absolute dietary intakes of genistein + daidzein was determined using the duplicate diet method.

Collection and analysis of duplicate diets is considered to be the 'gold standard' for accurate assessment of nutrient or non-nutrient intakes (Bingham et al. 1988). In the case of PO, lack of data available for a wide variety of UK foods meant that duplicate diet analysis was likely to be the most accurate method for determining dietary exposure to these compounds. In validating dietary intake data for PO, it is important to remember that whilst intakes in many western countries are often $<10 \mathrm{mg} / \mathrm{d}$, worldwide these can vary up to $100 \mathrm{mg} / \mathrm{d}$.

Biomarkers of intake need therefore to be valid over a wide range of intakes and we have therefore chosen to study individuals whose intakes ranged from $0-44 \mathrm{mg} / \mathrm{d}$.

\section{Subjects and methods \\ Subjects and study design}

Fourteen healthy volunteers, two male and twelve female, aged 21-76 years, were selected by dietary PO intake estimated in previous studies of vegetarians and omnivores and from a time course study investigating changes in PO 
intake over a 6-month period. Subjects were excluded if they had taken antibiotics within the previous 6 months. Weighed food diaries (7d) and estimated records previously obtained from volunteers and analysed for PO content (total genistein + daidzein) using a new database were used to identify a specific $24 \mathrm{~h}$ period. Volunteers were subsequently given a copy of the diet sheet from their earlier food record and asked to consume a similar food intake over the $24 \mathrm{~h}$ recording period of the duplicate diet collection, while completing $24 \mathrm{~h}$ weighed food diaries (Bingham et al. 1988). Complete duplicates of all foods eaten during the $24 \mathrm{~h}$ recording period, i.e. same weights of identical food items and in the same form as eaten (cooked or raw) were placed in a weighed collection container and stored in a fridge or cool room during collection (Bingham et al. 1988). Only beverages that were soyabeanbased, such as soya milk, were collected. The weights of other drinks were recorded, but duplicate portions were not collected. All complete duplicate diets were returned to Ninewells Hospital (Dundee, Scotland, UK). The individual weight of each diet + container was recorded and the actual weight (wet weight) of food present was noted. Containers + diets were stored at $-20^{\circ} \mathrm{C}$. After defrosting, diets were prepared for freeze-drying by the addition of a known weight of water $(700 \mathrm{~g})$ to the contents of the collection container. Homogenization was carried out using 'Robocoupe', courtesy of Baxters of Speyside (Fochabers, Scotland, UK). The extra water was necessary to ensure complete homogenization of the total diet by producing an adequate vortex from which representative samples of the diet were taken and placed in $100 \mathrm{~g}$ plastic sample containers before freeze-drying. Samples were stored at $-20^{\circ} \mathrm{C}$ before being freeze-dried using an Edwards freeze-drier (Thermo Savant, Holbrook, NY, USA). When sample weight remained constant, freezedrying was considered complete. Each diet sample was further mixed using a mortar and pestle before hydrolysis.
The study protocol is shown in Fig. 1. During the duplicate diet period, each volunteer completed a $24 \mathrm{~h}$ urine collection and took $3 \times 80 \mathrm{mg} p$-aminobenzoic acid (PABA) tablets to ensure completeness of the collection (Bingham \& Cummings, 1983). All urine collections were shaken well to ensure thorough mixing. Six portions of each collection were subsequently placed in plastic universal containers and stored at $-20^{\circ} \mathrm{C}$ until subsequent analysis for PABA to check for completion. Complete collections containing $>85 \%$ PABA were subsequently analysed for total genistein + daidzein. In one urine collection recovery was $<85 \%$ and the volunteer was asked to repeat the study.

The timing for collection of a single plasma sample was set at 17.30 hours. While this was a suitable time for volunteers and their work schedules, plasma taken at this time would be post consumption of two meals that were likely to contain bread or bakery products and therefore PO. Peak plasma genistein + daidzein concentrations are achieved 5-9h after ingestion of foods containing these compounds (Setchell et al. 2001; Richelle et al. 2002); therefore, plasma collected at 17.30 hours was deemed likely to contain maximum concentrations of genistein and daidzein.

Timed blood samples were collected in heparinized vacutainers and left overnight in a refrigerator to allow plasma to separate. Plasma was removed using a Pasteur pipette and stored at $-20^{\circ} \mathrm{C}$ until required for analysis.

\section{Analytical methods}

Determination of isoflavones in plasma and urine by liquid chromatogaphy-MS. The concentrations of genistein and daidzein in plasma and urine samples were measured using liquid chromatography (LC)-MS. Triply labelled $\left[{ }^{13} \mathrm{C}_{3}\right]-$ genistein and $\left[{ }^{13} \mathrm{C}_{3}\right]$ daidzein were used as internal standards and added to samples before hydrolysis. LC-MS or

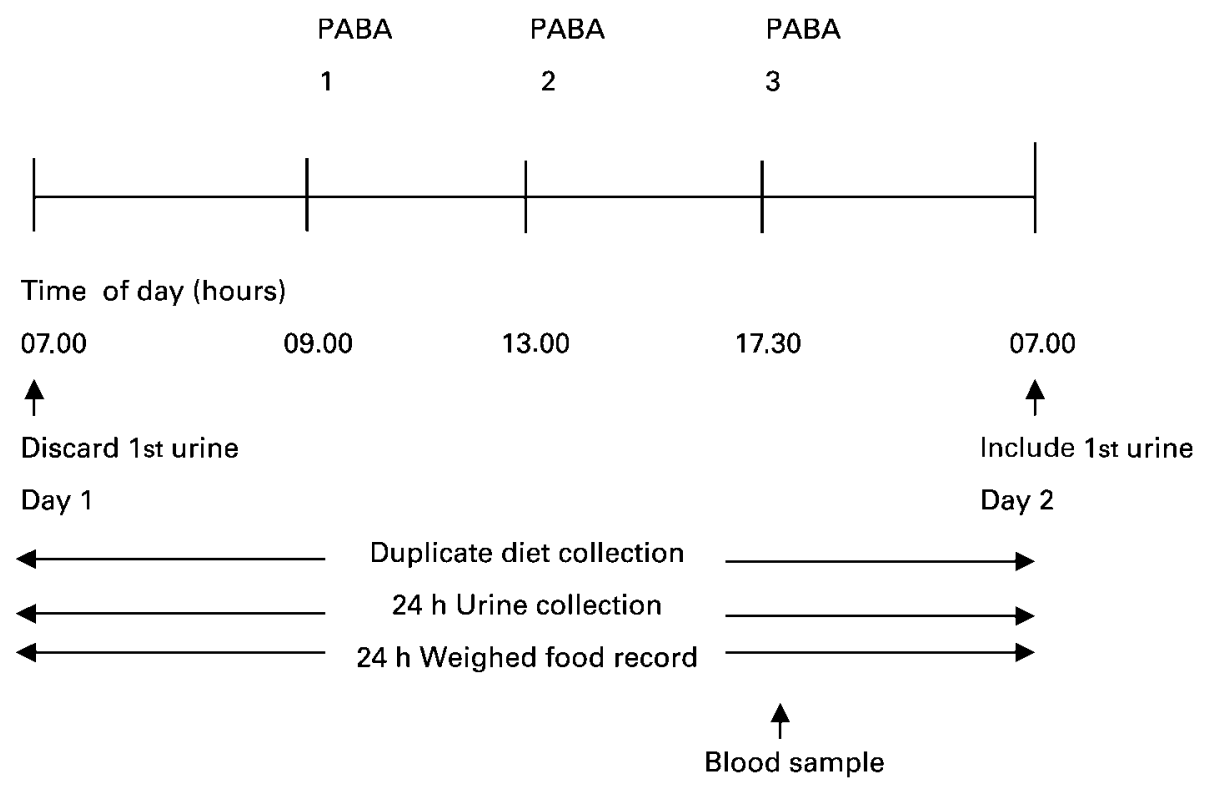

Fig. 1. Protocol for the present study. PABA, p-aminobenzoic acid. 
GC-MS are considered more accurate methods of analysis than HPLC. (Clarke et al. 2002; Grace et al. 2003a,b).

Chemicals and reagents. Toluene, $n$-heptane, methanol, chloroform, diethyl ether and ethyl acetate were of AnalaR ${ }^{\circledR}$ grade and were purchased from Merck BDH Ltd (Poole, Dorset, UK). Sephadex ${ }^{\circledR}$ LH-20 (bead size 25$100 \mu \mathrm{m}$, for gel filtration using organic solvents) was purchased from Amersham Pharmacia BioTech (St Albans, Herts., UK). $\beta$-Glucuronidase (from Helix pomatia, type H-3AF, containing sulfatase activity) was obtained from Sigma Chemical Co. Ltd (Poole, Dorset, UK). The enzyme solution containing activity of $127000 \mathrm{U} / \mathrm{ml}$ was prepared in $0 \cdot 1 \mathrm{M}$-sodium acetate buffer $(\mathrm{pH} 5 \cdot 0)$ to give $1000 \mathrm{U}$ per aliquot (1 U liberates $1 \mu \mathrm{g}$ phenolphthalein glucuronide per $\mathrm{h}$ at $37^{\circ} \mathrm{C}$ at $\mathrm{pH} 5 \cdot 0$ ). Dichlorodimethylsilane was purchased from Sigma Chemical Co. Ltd. All disposable and re-useable glassware was silanized before use. The glassware was soaked in a solution of dichlorodimethylsilane $(30 \mathrm{~g} / \mathrm{l}$ toluene) for 3-5 min (Pumford et al. 2002). Silanized glassware was first washed with toluene, twice with methanol and airdried. Resilanization of glassware was carried out by first steeping glassware in methanol for $24 \mathrm{~h}$ before repeating the silanization process.

Analytes. Daidzein (7,4'-dihydroxyisoflavone) and genistein $\left(5,7,4^{\prime}\right.$-trihydroxyisoflavone) were gifts from Dr Nigel Botting, University of St Andrews. Triply labelled ${ }^{13} \mathrm{C}_{3}$ internal standards of genistein and daidzein were also obtained from Dr Nigel Botting, University of St Andrews. Stock solution A containing $500 \mathrm{ng}$ genistein or daidzein/ $\mathrm{ml}$ was made up and used in the preparation of standard solutions for the calibration curve. Stock solution B containing $250 \mathrm{ng}$ triply labelled internal standards $/ 50 \mu \mathrm{l}$ was prepared. Both stock solutions were stored at $-20^{\circ} \mathrm{C}$.

Calibration curve. The calibration curve used for each assay was prepared from the methanolic stock solutions A and B. Clean silanized sample vials were labelled 0, 25, 50, 100,250 and 500 referring to the amount of unlabelled analyte in each. This was achieved by taking $0(500 \mu \mathrm{l}$ methanol was used), 50, 100, 200, 500 and $1000 \mu$ l stock solution $(500 \mathrm{ng} / \mathrm{ml})$ respectively. Triply labelled internal standard $(50 \mu \mathrm{l}$; containing $250 \mathrm{ng} / 50 \mu \mathrm{l})$ was added to each of the sample vials. The vials containing both normal and triply labelled internal standards were dried under a stream of $\mathrm{N}_{2}$ before redissolving the analytes in $80 \mu \mathrm{l}$ methanol-water $(1: 1, \mathrm{v} / \mathrm{v})$. Standards were subsequently analysed by LC-MS and a calibration curve obtained.

Sample hydrolysis and extraction. Urine and plasma samples were prepared according to the method of Pumford et al. (2002) and Morton et al. (2002), but omitting the derivatization step. Plasma and urine samples were defrosted fully before sampling. Internal standard solution (containing $250 \mathrm{ng}$ triply labelled internal standard/50 $\mu \mathrm{l}$ ) was allowed to equilibrate to room temp $\left(20-22^{\circ} \mathrm{C}\right)$ for at least $1 \mathrm{~h}$ before use. Plasma $(500 \mu \mathrm{l})$ or urine $(250 \mu \mathrm{l})$ were pipetted into Quickfit (NS 19/26) ground-glass-stoppered tubes. To ensure accuracy of pipetting, all portions were weighed. Enzyme solution containing $1000 \mathrm{U}$ activity in $0.1 \mathrm{M}$-sodium acetate, $\mathrm{pH} 5 \cdot 0$, was added, followed by the addition of a further $3 \mathrm{ml} 0 \cdot 1 \mathrm{M}$-sodium acetate, $\mathrm{pH}$ 5.0. Finally, $50 \mu \mathrm{l}$ internal standard cocktail was added to each sample using a $50 \mu \mathrm{l}$ syringe. Samples were then vortex mixed and subsequently incubated in a water-bath at $37^{\circ} \mathrm{C}$ overnight. After hydrolysis, the tubes were cooled and the aglycones extracted into ethyl acetate $(2 \times 4 \mathrm{ml})$. The aqueous layer was frozen by standing the tubes in a $\mathrm{NaCl}$-iced-water-bath for approximately $10 \mathrm{~min}$; the organic layer was then decanted into labelled, silanized glass tubes $(13 \times 100 \mathrm{~mm})$. The tubes were then placed in a heating block (Techne dri-block; Techne, Cambridge, UK); the contents were evaporated under a gentle stream of $\mathrm{N}_{2}$ at $55^{\circ} \mathrm{C}$. A sample tube containing only water as a procedural blank was also included in every run and processed identically to the study samples.

Sephadex ${ }^{\circledR}$ LH-20 chromatography. Samples were further cleaned up (de-lipidized) by Sephadex ${ }^{\circledR}$ LH-20 (Amersham Pharmacia BioTec) chromatography. For each column per sample, $350 \mathrm{mg}$ LH-20 was required. This was placed in a ground-glass-stoppered conical flask and approximately $50 \mathrm{ml}$ chloroform-heptane-methanol (10:10:1, by vol.) was added. The LH-20 was soaked in the solvent mixture for $10 \mathrm{~min}$ at room temperature. Silanized Pasteur pipettes, $150 \mathrm{~mm}$ long (shortened at the tip), were plugged with silanized glass wool and packed with the LH-20, which had been swollen, to give a column height of $35 \mathrm{~mm}$. (All silanized columns were marked at $35 \mathrm{~mm}$ from neck to assist with column preparation.) The dry extract from each sample was dissolved in chloroform-heptane-methanol (10:10:1, by vol.; $200 \mu \mathrm{l})$ with vortexing, and the contents of each tube were transferred to the top of each corresponding column using a clean silanized Pasteur pipette. This process was repeated using $200 \mu \mathrm{l}$ solvent mixture and the washings were transferred to the column. The columns were subsequently washed with $3.6 \mathrm{ml}$ solvent mixture, which was discarded. PO (genistein + daidzein) were eluted with $4 \times 1 \mathrm{ml}$ methanol into clean silanized test-tubes $(12 \times 75 \mathrm{~mm})$. Methanol was removed under $\mathrm{N}_{2}$ at $60^{\circ} \mathrm{C}$ until approximately $400 \mu \mathrm{l}$ solvent remained. Samples were then transferred to silanized sample vials by adding $1 \mathrm{ml}$ methanol to each test-tube and vortexing. All samples were blown down to dryness under $\mathrm{N}_{2}$. Finally, samples were dissolved in $80 \mu \mathrm{l}$ methanol-water $(1: 1, \mathrm{v} / \mathrm{v})$ and stored at $-20^{\circ} \mathrm{C}$ before LC-MS analysis.

Liquid chromatography-MS analysis. LC-MS was carried out by identification of the analyte molecular ions and internal standard molecular ions, $\mathrm{MH}^{+}$. The intensity (peak area) of the selected ions $\left(\mathrm{MH}^{+}\right)$for each analyte (e.g. genistein and daidzein) and each triply labelled internal standard, i.e. $\left[{ }^{13} \mathrm{C}_{3}\right]$ genistein and $\left[{ }^{13} \mathrm{C}_{3}\right]$ daidzein, were monitored, recorded and expressed as a ratio (peak area analyte:peak area ${ }^{13} \mathrm{C}_{3}$ internal standard) for each target compound and internal standard. Using the calibration curve (standard curve) of peak area ratio $v$. concentration of analyte produced by the calibration standards, the concentrations of the analyte in each of the samples could be calculated.

The LC-MS system used in the current work was a ThermoFinnigan Liquid Chromatography Quadrupole (LCQ-Deca; Thermofinnigan, Hemel Hempstead, Herts., $\mathrm{UK})$ ion-trap MS with on-axis electrospray interface. In order to carry out LC-MS analysis of urine and plasma 
samples, all samples underwent enzymatic hydrolysis before solid-phase extraction. Each sample ready for analysis was dissolved in $80 \mu \mathrm{l}$ methanol-water $(1: 1, \mathrm{v} / \mathrm{v})$. Injections of $5 \mu \mathrm{l}$ (using the surveyor autosampler) of each sample were used for analysis. Samples were analysed by electrospray ionization in positive ion mode using a column consisting of Ultra carb $\left(\mathrm{C}_{18}\right)$ (Phenomenex, Macclesfield, Ches., UK; $30 \% \mathrm{C}$ load, $5 \mu \mathrm{m}$, diameter $2 \mathrm{~mm}$, length $150 \mathrm{~mm}$, in reverse phase (increasing hydrophobicity with time)); the solvent gradient was $0 \%$ acetonitrile: $2 \%$ formic acid to $70 \%$ acetonitrile: $2 \%$ formic acid and the flow rate was $225 \mu \mathrm{l} / \mathrm{min}$. The run time per sample was 20 min. During LC-MS, identification of ions can be carried out in full-scan or selected-ion-monitoring mode. During analysis of samples in the present study, scanning was initially confined to mass range 240-320 (unless identification of glycosides was necessary). Thereafter, daidzein was identified at $\mathrm{m} / \mathrm{z} 254 \cdot 5-255 \cdot 5$, daidzein internal standard was identified at $\mathrm{m} / \mathrm{z} 257 \cdot 5-258 \cdot 5$, genistein was identified at $\mathrm{m} / \mathrm{z} \quad 270.5-271.5$ and genistein internal standard was identified at $\mathrm{m} / \mathrm{z} 273 \cdot 5-274 \cdot 5$.

Electrospray ionization was used in preference to atmospheric pressure chemical ionization because it is ideally suited to the analysis of pre-existing (in solution) ions. The optimum flow rate for electrospray ionization is approximately $100-300 \mu \mathrm{l} / \mathrm{min}$, allowing infusion of solutions using a syringe pump. Atmospheric pressure chemical ionization can be used at flow rates of 0.2 to $1.0 \mathrm{ml} / \mathrm{min}$ if the proportion of water being used in the mobile phase is low, but the slower flow rate using electrospray ionization was considered to be capable of producing more accurate results in the current set of analyses. Formic acid was used as a proton donor to allow formation of the $\mathrm{MH}^{+}$ion.

Conversion of analyte peak height:internal standard peak height relative response ratio to PO concentrations in SI units was carried out using the equations as follows:

$$
\begin{aligned}
\text { genistein }(\mathrm{mol} / 80 \mu \mathrm{l}(\mathrm{M}))= & \text { relative response ratio } \\
& \times 1.15741 \mathrm{e}^{-0.5}, \\
\text { formula weight genistein }= & 270 \text { atomic mass units, }
\end{aligned}
$$

genistein $(\mathrm{g} / \mathrm{ml})=(21.6 \times \mathrm{M}) /$ weight of sample $(\mu \mathrm{g})$ and

$$
\begin{aligned}
\text { daidzein }(\mathrm{mol} / 80 \mu \mathrm{l}(\mathrm{M}))= & \text { relative response ratio } \\
& \times 1.23031 \mathrm{e}^{-0.5}, \\
\text { formula weight daidzein }= & 254 \text { atomic mass units, }
\end{aligned}
$$

daidzein $(\mathrm{g} / \mathrm{ml})=(20 \cdot 32 \times \mathrm{M}) /$ weight of sample $(\mu \mathrm{g})$.

The relative response ratio is $<10$. If the relative response ratio was $>10$, then sample analysis was repeated using a smaller amount of sample, e.g. if relative response ratio was 20 , then sample weight was reduced by a factor of three to four such that $250 \mu \mathrm{g}$ urine $\rightarrow 80 \mu \mathrm{g}$ urine for repeat analysis. The limits of detection for plasma using these equations were: genistein $10 \mathrm{ng}(0.04 \mu \mathrm{mol}) / \mathrm{l})$ (relative response ratio 0.02$)$; daidzein $10 \mathrm{ng}(0.04 \mu \mathrm{mol}) / \mathrm{l})$ (relative response ratio 0.02).

Intra- and inter-assay $C V$ for plasma and urine analyses. The intra-assay CV for LC-MS analyses were calculated from the relative response ratios obtained from repeat analysis of twelve samples. The CV for genistein and daidzein were 9.2 and $11.6 \%$ respectively. Intra-assay CV for plasma genistein and daidzein were 5.0 and $4.0 \%$ respectively (determined using sixteen samples). Inter-assay CV for plasma genistein and daidzein were 13.7 and $14.3 \%$ respectively (determined using twelve samples). Intra-assay CV for urinary genistein and daidzein were 8.0 and $5.5 \%$ respectively (determined from replicate (twenty-two) preparations of one sample). Inter-assay CV for urinary genistein and daidzein were 17.0 and $17.0 \%$ respectively (determined using twelve samples).

The recovery of genistein and daidzein internal standards during processing, i.e. sample clean up was 70 and $72 \%$ respectively. This was acceptable, since some sample was lost during 'clean-up'; however, the addition of an internal standard allows for reduction in sample recovery.

\section{Determination of isoflavones in duplicate diet samples}

Chemicals and reagents. Diethyl ether, methanol, sodium acetate, $n$-heptane and chloroform were of Analar ${ }^{\circledR}$ grade and were purchased from Merck BDH Ltd. Sephadex ${ }^{\circledR}$ LH-20 was purchased from Amersham Pharmacia BioTech. All glassware was silanized before use.

Analytes. Internal standard containing $\left[{ }^{13} \mathrm{C}_{3}\right]$ genistein and $\left[{ }^{13} \mathrm{C}_{3}\right.$ ]daidzein $(250 \mathrm{ng} / 50 \mu \mathrm{l})$ was used for all diet analyses.

Sample hydrolysis and extraction. Freeze-dried diets were mixed using a mortar and pestle and analysed in triplicate using LC-MS according to the method used by Wang et al. (1990) with modifications. $\mathrm{HCl}(10 \mathrm{ml} / \mathrm{l})$ was used instead of $1 \mathrm{M}-\mathrm{HCl}$ and repeat hydrolysis was carried out at $60-70^{\circ} \mathrm{C}$ for $24 \mathrm{~h}$ with stirring rather than for $2 \mathrm{~h}$ at $98-100^{\circ} \mathrm{C}$. A sample $(500 \mathrm{mg})$ of each freeze-dried diet (calculated to produce a relative response ratio in the required range from the maximum estimated $\mathrm{PO}$ content of the duplicate diets) was placed in a glass screw-top universal container to which $12.5 \mathrm{ml} \mathrm{HCl}(10 \mathrm{ml} / \mathrm{l})$ in methanol-water (80:20, v/v) was added. Containers were placed in a water-bath at $60-65^{\circ} \mathrm{C}$ and contents stirred for $24 \mathrm{~h}$. After cooling, samples were centrifuged at $4000 \mathrm{rpm}$ for 10 min. The supernatant fraction was collected into a weighed container and hydrolysis of the pellet repeated with the addition of $12.5 \mathrm{ml} \mathrm{HCl}(10 \mathrm{ml} / \mathrm{l})$ in methanolwater $(80: 20, \mathrm{v} / \mathrm{v})$. Samples were replaced in a water-bath at $60-65^{\circ} \mathrm{C}$ for a further $24 \mathrm{~h}$ with stirring. After cooling and centrifugation, supernatant fractions were pooled and made up to weight with $25 \mathrm{ml}$ methanol-water $(80: 20$, v/v), i.e. weight of container $+21 \cdot 2145 \mathrm{~g}$. Hydrolysed samples were stored at $-20^{\circ} \mathrm{C}$. Measurements of genistein and daidzein were carried out by weighing $1 \mathrm{ml}$ mixed supernatant fractions into silanized labelled Quickfit (NS 19/26) ground-glass-stoppered tubes. Internal standard

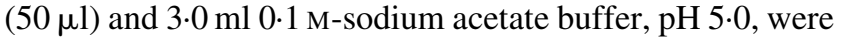
added and the mixture vortexed. Diethyl ether $(4 \mathrm{ml})$ was added to each test-tube and the contents shaken gently (to avoid an emulsion) for $1 \mathrm{~min}$. Test-tubes were subsequently left to stand for 5-10 min, during which time 
the diethyl ether layer separated from the aqueous layer and was removed with a Pasteur pipette. Samples were blown down gently under $\mathrm{N}_{2}$ at $30^{\circ} \mathrm{C}$. Sample 'clean-up' was carried out using Sephadex ${ }^{\circledR}$ LH-20 (Amersham Pharmacia BioTec) columns as detailed previously (p. 449). All samples were finally dissolved in $80 \mu \mathrm{l}$ methanol-water $(1: 1, \mathrm{v} / \mathrm{v})$ before LC-MS analysis.

Completion of hydrolysis. It was necessary to ascertain the optimum conditions for complete hydrolysis of genistein and daidzein glycosides. This was achieved in three ways.

(1) One sample (A) identified to be high in PO glycosides was hydrolysed with repeated hydrolysis over different time periods $(2,4$ and $24 \mathrm{~h}$ ). The $\mathrm{HCl}$ concentration was also altered. The genistein and daidzein concentrations in each timed sample were measured.

(2) Identification of non-hydrolysed glycoside peaks was also carried out by scanning peaks at mass $417\left(\mathrm{M}^{+}\right)$ for daidzin, $433\left(\mathrm{MH}^{+}\right)$for genistin. Absence of these peaks indicated complete hydrolysis.

(3) Dried soya milk, rich in acetyl glycosides was hydrolysed for $24 \mathrm{~h}$ repeat. Analysis of the chromatogram did not yield any peaks corresponding to mass 417 for daidzin or 433 for genistin. Furthermore, any additional $24 \mathrm{~h}$ hydrolysis of samples already hydrolysed for $24 \mathrm{~h}$ did not yield any more genistein or daidzein, indicating that all hydrolysis was complete and all aglucones had been extracted.

Intra- and inter-assay $C V$ for duplicate diet analyses. Intra-assay $\mathrm{CV}$ for duplicate diet genistein and daidzein were 15.2 and $15.2 \%$ respectively (determined from analyses of fifteen diets in triplicate, one diet repeated). Inter-assay $\mathrm{CV}$ for duplicate diet genistein and daidzein were 15.5 and $6.8 \%$ respectively (determined from repeat analysis of one diet in triplicate).

\section{Statistical analyses}

Statistical analysis was performed using Microsoft 'Excel' for Windows 98 (Microsoft, Redmond, WA, USA).

\section{Results}

\section{Subject characteristics and compliance}

Fourteen subjects successfully completed the duplicate diet collection and urine collection over the $24 \mathrm{~h}$ period. Eleven subjects provided a timed blood sample.

\section{Comparison of estimated and measured genistein and daidzein content of diets (Table 1)}

Using the food diaries and new PO database, individual estimated dietary total PO (genistein + daidzein) intakes were calculated from recorded weights of foods and beverages consumed during the $24 \mathrm{~h}$ recording period. The range of total genistein + daidzein intake was $1 \cdot 18-43.40 \mathrm{mg}$ and $0.01-46.40 \mathrm{mg}$ for measured and estimated values respectively. Mean total dietary genistein and daidzein contents were $12.26 \mathrm{mg}$ (estimated) and $11.03 \mathrm{mg}$ (measured).
Table 1. Total genistein + daidzein intake $(\mathrm{mg} / \mathrm{d})$ measured by liquid chromatography-MS analysis of duplicate diets or from food diaries and phyto-oestrogen database

\begin{tabular}{lcc}
\hline $\begin{array}{l}\text { Volunteer } \\
\text { identity }\end{array}$ & $\begin{array}{c}\text { Estimated PO } \\
\text { intake (diary) }\end{array}$ & $\begin{array}{c}\text { Measured PO intake } \\
\text { (duplicate diet) }\end{array}$ \\
\hline T & 0.01 & 1.56 \\
V & 0.22 & 3.41 \\
N & 0.32 & 1.18 \\
P & 0.33 & 2.60 \\
X & 0.42 & 2.70 \\
K & 0.52 & 2.17 \\
H & 9.03 & 5.23 \\
R & 11.41 & 12.36 \\
Q & 11.62 & 10.80 \\
Z & 18.93 & 14.50 \\
S & 19.35 & 14.90 \\
G & 20.60 & 17.30 \\
B & 32.53 & 22.30 \\
D & 46.40 & 43.40 \\
Mean & 12.26 & 11.03 \\
SEM & 3.79 & 3.09 \\
\hline
\end{tabular}

$\mathrm{PO}$, phyto-oestrogen.

Figure 2 compares individual estimated intake of total genistein + daidzein with measured intake $(\mathrm{mg})$. The correlation coefficient between estimated PO intake and measured PO intake was 0.98 and the equation of the line indicating the relationship between measured and estimated intakes $y=0 \cdot 80 x+1 \cdot 24$. Measured PO intake therefore represented approximately $80 \%$ of intake estimated from a diet diary, i.e the database tended to overestimate intake. However, this relationship varied depending on PO intake being high, intermediate or low.

Six of the fourteen diets contained very low amounts of estimated genistein + daidzein, i.e. $<1 \mathrm{mg} / \mathrm{d}$, whereas the range of measured genistein + daidzein amounts in these diets was $1.18-3.41 \mathrm{mg}$. These diets did not contain foods identified as being derived from soyabean, although soya flour had been added to a variety of breads as indicated from food labels collected by the subjects. As a

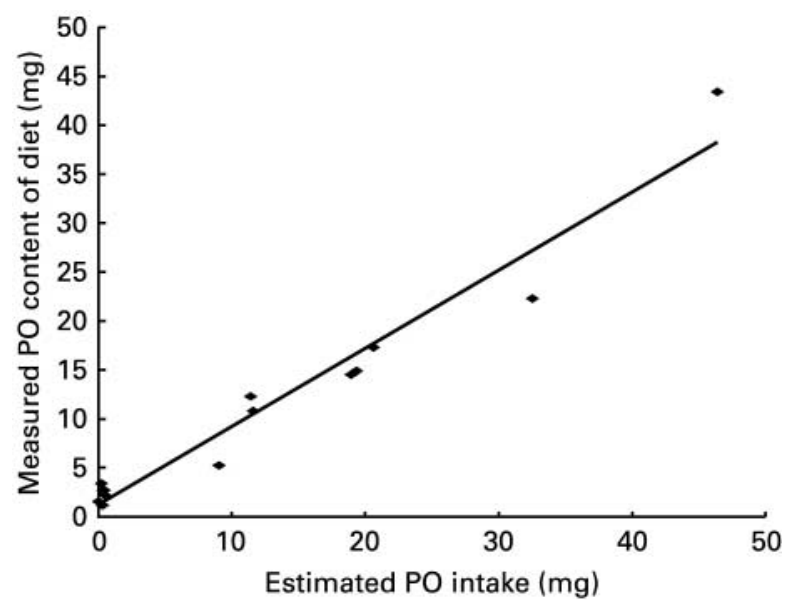

Fig. 2. Relationship between measured total genistein + daidzein intake using liquid chromatography-MS analysis of duplicate diets (mg) $v$. total estimated genistein + daidzein intake $(\mathrm{mg})$ from food diaries and phyto-oestrogen (PO) database $(y=0.80 x+1.24$; $r 0.98, P<0.001)$. For details of subjects, diets and procedures, see Table 1 and pp. 447-451. 
result, the estimated PO content was mainly based on genistein + daidzein values for bread (Liggins et al. $1998,2002)$ and was due to the addition of soya flour to bakery products (Liggins et al. 2002). Even allowing for the addition of soya flour to bakery products, estimated genistein + daidzein intakes were lower than measured intakes (at low intakes). Therefore, for dietary PO intakes $<5 \mathrm{mg} / \mathrm{d}$, the database underestimates intake. For genistein + daidzein intakes in the estimated range 9-33 mg, which related to foods containing added soyabean or derived from soyabean, the estimated intake was higher. For the estimated intake of $46.40 \mathrm{mg}$, the measured value was $43.40 \mathrm{mg}$; therefore, at this higher PO intake, the estimated intake reflected measured intake more closely. Since one volunteer (D) consumed a diet containing $>40 \mathrm{mg}$ PO, the effect of excluding this subject's measured PO intake and estimated values on the relationship between measured intake and estimated intake was assessed (results not shown). The relationship between measured intake and estimated intake was $\mathrm{y}=0 \cdot 66 x+2 \cdot 2$ ( $r 0.98, P<0.001$ ). By excluding values for $\mathrm{D}$, background exposure increased from 1.20 to $2.20 \mathrm{mg}$. In addition, measured PO intake represented approximately $66 \%$ of intake. The relationship between measured and estimated PO intake remained highly significant.

\section{Correlation of urinary genistein + daidzein with measured dietary intake}

Urinary p-aminobenzoic acid recovery (Table 2). Overall PABA recovery was 97 (SEM 2) \%. One volunteer (N) lost some urine during the $24 \mathrm{~h}$ collection due to a spillage. A repeat duplicate diet and $24 \mathrm{~h}$ urine collection with timed plasma sample was carried out. The repeat collection was analysed for PABA and recovery was $87 \%$; therefore the urine collection was deemed complete. All complete

Table 2. $p$-Aminobenzoic acid (PABA) recovery (\%) in $24 \mathrm{~h}$ urine collections for volunteers carrying out duplicate recording and collection* $\dagger$

\begin{tabular}{lc}
\hline Volunteer identity & PABA recovery (\%) \\
\hline T & 85 \\
$\mathrm{~N} \ddagger$ & $80 \ddagger$ \\
$\mathrm{X}$ & 108 \\
$\mathrm{H}$ & 102 \\
$\mathrm{Q}$ & 102 \\
$\mathrm{~S}$ & 93 \\
$\mathrm{D}$ & 92 \\
$\mathrm{~V}$ & 102 \\
$\mathrm{P}$ & 112 \\
$\mathrm{~K}$ & 92 \\
$\mathrm{R}$ & 98 \\
$\mathrm{Z}$ & 98 \\
$\mathrm{G}$ & 101 \\
$\mathrm{~B}$ & 92 \\
\hline
\end{tabular}

* For details of subjects and procedures, see pp. 447-448.

† Mean PABA recovery (including repeat urine collection) was 97 (SEM 2) \%. $\ddagger$ This volunteer lost some urine during the $24 \mathrm{~h}$ collection due to a spillage. A repeat duplicate diet and $24 \mathrm{~h}$ urine collection with timed plasma sample was carried out. The repeat urine collection was analysed for PABA and recovery was $87 \%$; therefore, the urine collection was deemed complete. All $24 \mathrm{~h}$ urine collections were subsequently analysed for genistein and daidzein using liquid chromatography-MS. urine collections were subsequently analysed for total genistein + daidzein.

Total $24 \mathrm{~h}$ urinary genistein + daidzein (Table 3). Urinary excretion of daidzein was greater than that of genistein. The mean value for daidzein in $24 \mathrm{~h}$ urine collections was $71 \%$ of that for total genistein + daidzein, which agrees with previous published results (Kelly et al. 1995; Irvine et al. 1998; Habito et al. 2000; Rowland et al. 2000; Uehara et al. 2000; Yamamoto et al. 2001; Franke et al. 2002; Richelle et al. 2002; Tsunoda et al. 2002).

Figure 3 compares total urinary genistein + daidzein with measured dietary intake. The equation of the line is $y=0.22 x-0.08(r 0.97, P<0.001)$. While there is excellent agreement between $24 \mathrm{~h}$ measured dietary intake of total genistein + daidzein and $24 \mathrm{~h}$ urinary excretion, urine excretion of genistein + daidzein comprises only $23 \%$ of intake.

For two volunteers in the present study, urinary excretion of genistein + daidzein did not follow the normal trend. These volunteers are identified as $\mathrm{Q}$ and R. Urinary excretion $(24 \mathrm{~h})$ for $\mathrm{Q}$ was $1.21 \mathrm{mg}$ compared with a measured intake of total genistein + daidzein of $10.80 \mathrm{mg}$. i.e. $8 \%$ of intake. For volunteer $\mathrm{R}$ intake was $12.36 \mathrm{mg}$ and $24 \mathrm{~h}$ urine excretion was $4.35 \mathrm{mg}$, i.e. $35 \%$ of dietary intake. By excluding dietary intake and urinary excretion values for volunteer $\mathrm{D}$, as explained earlier, the relationship between measured intake and $24 \mathrm{~h}$ urinary excretion was $y=0.23 x-0.02(r 0.94, P<0.001)$.

Correlation of genistein + daidzein concentrations in timed plasma samples with measured dietary intake (Table 4). Analysis of eleven timed plasma samples for genistein + daidzein revealed that mean concentrations of genistein were $53 \%$ of total genistein + daidzein concentration.

Figure 4 compares concentrations of genistein and daidzein in timed plasma samples with measured dietary

Table 3. Results of liquid chromatography-MS analysis of $24 \mathrm{~h}$ urine for genistein (G), daidzein (D) and genistein + daidzein $(\mathrm{G}+\mathrm{D})(\mathrm{mg})$ with corresponding genistein + daidzein levels from liquid chromatography-MS analysis of duplicate diets $(\mathrm{mg})^{*}$

\begin{tabular}{|c|c|c|c|c|c|c|}
\hline \multirow[b]{2}{*}{$\begin{array}{l}\text { Volunteer } \\
\text { identity }\end{array}$} & \multicolumn{3}{|c|}{ Measured dietary } & \multicolumn{3}{|c|}{$24 \mathrm{~h}$ urinary } \\
\hline & $\mathrm{D}$ & $\mathrm{G}$ & $G+D$ & $\begin{array}{c}\mathrm{PO} \\
(\mathrm{G}+\mathrm{D})\end{array}$ & $\mathrm{D}$ & $\mathrm{G}$ \\
\hline $\mathrm{N}$ & 0.73 & 0.45 & $1 \cdot 18$ & 0.36 & 0.13 & 0.23 \\
\hline $\mathrm{T}$ & 0.31 & $1 \cdot 25$ & 1.56 & 0.17 & 0.10 & 0.07 \\
\hline K & 0.56 & 1.61 & $2 \cdot 17$ & 0.36 & 0.29 & 0.07 \\
\hline $\mathrm{P}$ & $1 \cdot 25$ & 1.35 & $2 \cdot 60$ & 0.55 & 0.48 & 0.07 \\
\hline $\mathrm{X}$ & 1.08 & 1.62 & $2 \cdot 70$ & 0.73 & 0.54 & 0.19 \\
\hline V & 2.05 & 1.36 & 3.41 & $1 \cdot 11$ & 0.71 & 0.40 \\
\hline $\mathrm{H}$ & $2 \cdot 25$ & 2.98 & $5 \cdot 23$ & $1 \cdot 18$ & 1.00 & 0.18 \\
\hline$Q$ & 4.97 & 5.83 & $10 \cdot 80$ & $1 \cdot 21$ & 1.01 & 0.20 \\
\hline $\mathrm{R}$ & $6 \cdot 18$ & $6 \cdot 18$ & $12 \cdot 36$ & $4 \cdot 35$ & 4.00 & 0.35 \\
\hline Z & $5 \cdot 36$ & $9 \cdot 14$ & 14.50 & 3.06 & $2 \cdot 36$ & 0.70 \\
\hline $\mathrm{S}$ & 5.96 & 8.94 & 14.90 & $2 \cdot 70$ & $2 \cdot 27$ & 0.43 \\
\hline $\mathrm{G}$ & 8.65 & 8.65 & $17 \cdot 30$ & $4 \cdot 31$ & $2 \cdot 71$ & 1.60 \\
\hline$B$ & 6.69 & $15 \cdot 61$ & $22 \cdot 30$ & $5 \cdot 30$ & $3 \cdot 61$ & 1.69 \\
\hline D & $21 \cdot 27$ & $22 \cdot 13$ & 43.40 & $9 \cdot 24$ & $5 \cdot 24$ & 4.00 \\
\hline Mean & 4.81 & $6 \cdot 22$ & 11.03 & 2.48 & 1.75 & 0.73 \\
\hline SEM & 1.46 & 1.69 & $3 \cdot 10$ & 0.70 & 0.40 & 0.30 \\
\hline
\end{tabular}

PO, phyto-oestrogen.

${ }^{*}$ For details of subjects and procedures, see pp. 447-451. 


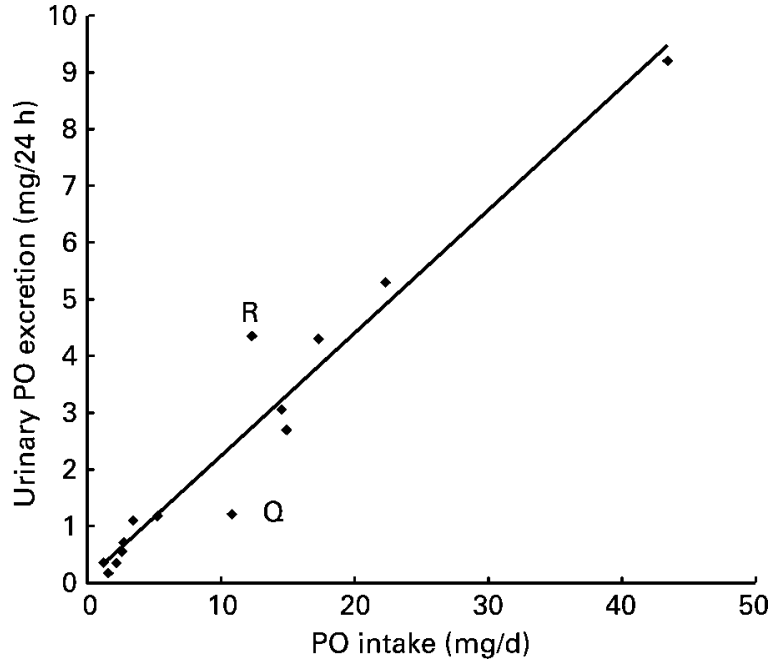

Fig. 3. The relationship between $24 \mathrm{~h}$ urinary genistein + daidzein (mg) measured by liquid chromatography-MS and measured dietary genistein + daidzein intake $(\mathrm{mg})(y=0.22 x+0.08 ; \quad r \quad 0.97$, $P<0.001)$. PO, phyto-oestrogen. For details of subjects, diets and procedures, see Table 1 and pp. 447-451. R and Q are outliers. $Q$ was a low excretor of genistein and daidzein and $R$ is a high excretor.

intake. The $r$ value of 0.92 indicated plasma PO correlated well with dietary PO intake $(P<0.001)$. Analysis of plasma from volunteers $\mathrm{Q}$ and $\mathrm{R}$ for total genistein+daidzein indicated that samples contained concentrations which did not follow the observed trend between dietary PO intake and plasma PO. Q was already identified as a low excretor of genistein + daidzein (compared with dietary intake) and $\mathrm{R}$ identified as a high excretor of genistein + daidzein. From Fig. 4, plasma concentrations of total genistein + daidzein for $\mathrm{R}$ were higher than the observed trend and plasma levels for Q lower than the observed trend.

When intake and plasma $\mathrm{PO}$ values for volunteer $\mathrm{D}$ were excluded, the $r$ value of 0.82 and $P<0.01$ indicated that the relationship was still very significant. The slightly lower $P$ value was due to the reduction in volunteer numbers.
Comparison of percentage intake of genistein and daidzein with percentage excretion in $24 \mathrm{~h}$ urine (Table 5). The percentage contribution of genistein and daidzein to each duplicate diet was calculated and compared with the percentage of genistein and daidzein excreted in each $24 \mathrm{~h}$ urine collection. For duplicate diets the mean contribution of genistein to total genistein and daidzein intake was $57 \%$ (43\% for daidzein). The mean genistein excreted in the urine was $28 \%$ ( $72 \%$ for daidzein).

Figure 5 compares concentrations of genistein + daidzein in timed plasma samples with total $24 \mathrm{~h}$ urinary excretion. The equation of the line is $y=42 \cdot 29 x+13 \cdot 23$. Correlation ( $r$ ) 0.99 indicates a very good relationship between PO concentrations in the timed plasma sample and PO concentrations in the $24 \mathrm{~h}$ urine collection $(P<0 \cdot 001)$. By excluding the values for volunteer $\mathrm{D}$, as discussed earlier, the equation of the line was $y=43.38 x+6.76$ ( $r$ 0.97, $P<0 \cdot 001)$.

\section{Discussion}

The high specificity and sensitivity of the LC-MS method used for sample analysis contributed to the accuracy of PO measurements in the present study. In addition, accuracy of results for analyses of diets, plasma and urine for genistein and daidzein were improved with the use of chemically stable, triply labelled ${ }^{13} \mathrm{C}_{3}$ isotopes of genistein and daidzein as internal standards. ${ }^{2} \mathrm{H}$-labelled analytes are less stable and can undergo $\mathrm{H}-{ }^{2} \mathrm{H}$ exchange.

Previous work by Lampe et al. (1999), Arai et al. (2000), Ritchie et al. (2001), Yamamoto et al. (2001), Frankenfeld et al. (2002) and Verkasalo et al. (2001) indicated a correlation of urine excretion and/or plasma PO with dietary PO intake. Only Frankenfeld et al. (2002) and Verkasalo et al. (2001) have investigated correlations between dietary intake and plasma concentrations in western populations. Frankenfeld et al. (2002) validated a food-frequency questionnaire (FFQ) developed by Kirk et al. (1999) for use in assessing dietary PO intake

Table 4. Concentrations of genistein (G), daidzein (D) and genistein + daidzein (G + D) (ng/ml) in timed plasma samples measured by liquid chromatography-MS analysis compared with total genistein + daidzein $(G+D)(m g)$ obtained from liquid chromatography-MS analysis of the corresponding duplicate diets ${ }^{\star} \dagger$

\begin{tabular}{|c|c|c|c|c|c|c|}
\hline \multirow[b]{2}{*}{ Volunteer identity } & \multicolumn{3}{|c|}{ Measured dietary } & \multicolumn{3}{|c|}{ Plasma } \\
\hline & $\mathrm{D}$ & $\mathrm{G}$ & $\mathrm{PO}$ & $P O(G+D)$ & $\mathrm{D}$ & $\mathrm{G}$ \\
\hline $\mathrm{T}$ & 0.31 & $1 \cdot 25$ & 1.56 & $22 \cdot 90$ & $14 \cdot 90$ & $8 \cdot 00$ \\
\hline $\mathrm{N}$ & 0.73 & 0.45 & $1 \cdot 18$ & 41.50 & 22.50 & $19 \cdot 00$ \\
\hline K & 0.56 & 1.61 & $2 \cdot 17$ & 38.40 & $24 \cdot 40$ & $14 \cdot 00$ \\
\hline$P$ & $1 \cdot 25$ & 1.35 & $2 \cdot 60$ & $26 \cdot 60$ & $17 \cdot 40$ & $9 \cdot 20$ \\
\hline$X$ & 1.08 & 1.62 & $2 \cdot 70$ & $38 \cdot 30$ & $16 \cdot 30$ & $22 \cdot 00$ \\
\hline Q & 4.97 & $5 \cdot 83$ & $10 \cdot 80$ & 28.50 & $17 \cdot 50$ & $11 \cdot 00$ \\
\hline $\mathrm{R}$ & $6 \cdot 18$ & $6 \cdot 18$ & $12 \cdot 30$ & 232.90 & 134.90 & $98 \cdot 00$ \\
\hline S & $5 \cdot 96$ & 8.94 & 14.90 & 95.00 & $47 \cdot 00$ & $48 \cdot 00$ \\
\hline $\mathrm{G}$ & 8.65 & 8.65 & $17 \cdot 30$ & $167 \cdot 80$ & $70 \cdot 80$ & 97.00 \\
\hline$B$ & 6.69 & $15 \cdot 61$ & $22 \cdot 30$ & $246 \cdot 80$ & $115 \cdot 80$ & $131 \cdot 00$ \\
\hline $\mathrm{D}$ & $21 \cdot 27$ & $22 \cdot 13$ & 43.40 & 401.80 & $127 \cdot 80$ & 274.00 \\
\hline Mean & $5 \cdot 24$ & 6.69 & 11.93 & $121 \cdot 86$ & $55 \cdot 39$ & 66.47 \\
\hline SEM & 1.84 & 2.08 & 3.87 & 37.98 & $14 \cdot 72$ & 24.70 \\
\hline
\end{tabular}

$\mathrm{PO}$, phyto-oestrogen.

${ }^{*}$ For details of subjects and procedures, see pp. 447-451.

†Eleven of the fourteen volunteers who participated in the study provided a plasma sample. 


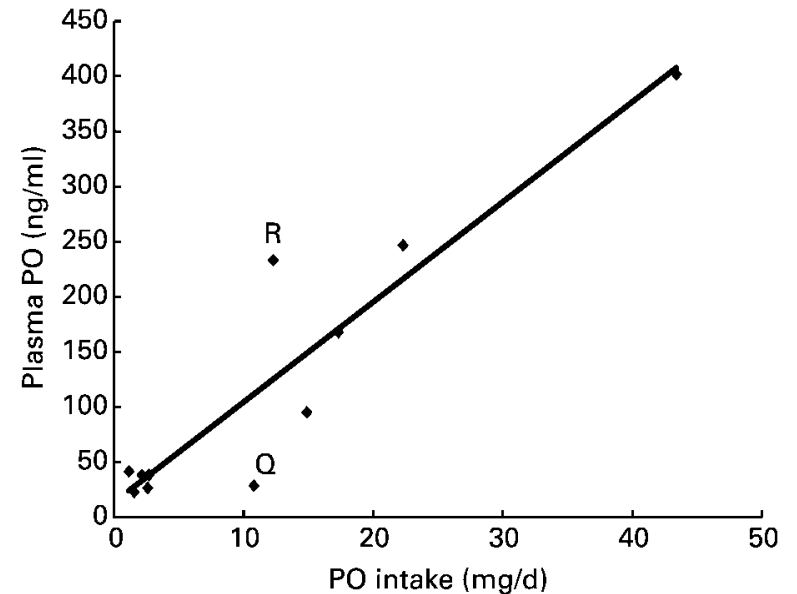

Fig. 4. Relationship between measured dietary genistein + daidzein intake $(\mathrm{mg})$ and concentrations of genistein + daidzein in a timed spot plasma sample $(\mathrm{ng} / \mathrm{ml})(y=9.08 x+13.53 ; r 0.92, P<0.001)$. $\mathrm{PO}$, phyto-oestrogen. For details of subjects, diets and procedures, see Table 1 and pp. 447-451. R and $Q$ are outliers. Plasma concentrations of genistein + daidzein for $R$ are higher than the observed trend and lower than the observed trend for $Q$.

of western populations. Kirk et al. (1999) administered the FFQ twice and produced correlation coefficients by comparing the mean soyabean-based food servings per month reported with each administration of the FFQ. The databases used for estimation of PO intake were provided by Coward et al. (1993), Wang \& Murphy (1994a,b), Reinli \& Block (1996) and the US Department of AgricultureIowa State University (1999), where PO values from foods were obtained by HPLC analysis.

Yamamoto et al. (2001) validated a FFQ using data for the PO content of food obtained from work carried out by Arai et al. (2000). The FFQ was subsequently used to estimate PO intake in Japanese populations.

No analysis of duplicate diets or composite diets was carried out during these studies; therefore, absolute values of dietary PO intake were not established. Although

Table 5. Comparison of genistein and daidzein intake (\%) with genistein and daidzein (\%) excreted in urine*

\begin{tabular}{lcccc}
\hline $\begin{array}{l}\text { Volunteer } \\
\text { identity }\end{array}$ & $\begin{array}{c}\text { Genistein in } \\
\text { diet (\%) }\end{array}$ & $\begin{array}{c}\text { Daidzein in } \\
\text { diet (\%) }\end{array}$ & $\begin{array}{c}\text { Urinary } \\
\text { genistein } \\
(\%)\end{array}$ & $\begin{array}{c}\text { Urinary } \\
\text { daidzein } \\
(\%)\end{array}$ \\
\hline $\mathrm{N}$ & 38 & 62 & 64 & 36 \\
$\mathrm{~T}$ & 80 & 20 & 41 & 59 \\
$\mathrm{~K}$ & 74 & 26 & 19 & 81 \\
$\mathrm{P}$ & 52 & 48 & 13 & 87 \\
$\mathrm{X}$ & 60 & 40 & 26 & 74 \\
V & 40 & 60 & 36 & 64 \\
$\mathrm{H}$ & 57 & 43 & 15 & 85 \\
$\mathrm{Q}$ & 54 & 46 & 17 & 83 \\
$\mathrm{R}$ & 50 & 50 & 8 & 92 \\
$\mathrm{Z}$ & 63 & 37 & 23 & 77 \\
$\mathrm{~S}$ & 60 & 40 & 16 & 84 \\
$\mathrm{G}$ & 50 & 50 & 37 & 63 \\
$\mathrm{~B}$ & 70 & 30 & 32 & 68 \\
$\mathrm{D}$ & 51 & 49 & 43 & 57 \\
Mean & 57 & 43 & 28 & 72 \\
SEM & 3 & 3 & 4 & 4 \\
\hline
\end{tabular}

${ }^{*}$ For details of subjects and procedures, see pp. 447-451.

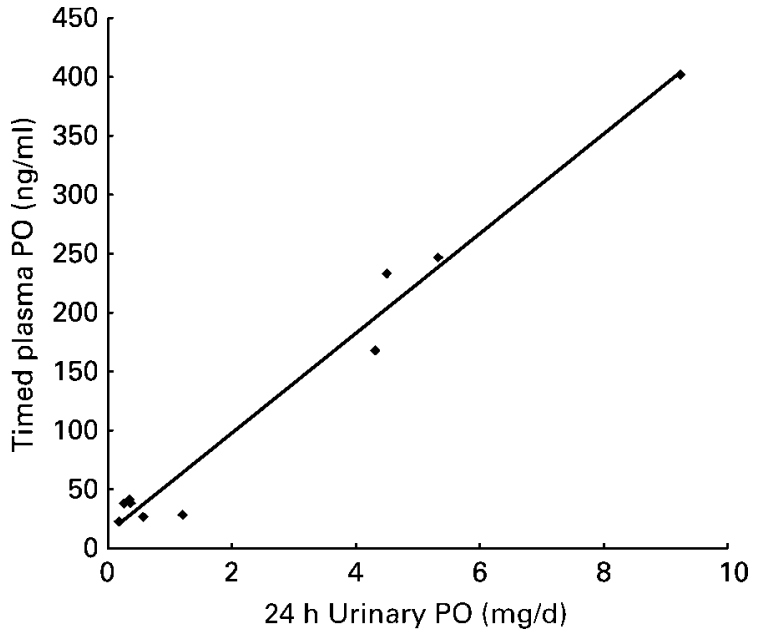

Fig. 5. Relationship between concentrations of genistein + daidzein $(\mathrm{ng} / \mathrm{ml})$ in timed plasma samples and $24 \mathrm{~h}$ urinary excretion of genistein + daidzein (mg) $(y=42.29 x+13.23 ; \quad r$ 0.99, $P<0.001$, $n$ 11). PO, phyto-oestrogen. For details of subjects, diets and procedures, see Table 1 and pp. 447-450.

correlations between dietary intake of PO with 24 h urinary excretion and plasma PO were noted, dietary intake data were based on estimated values and were therefore less accurate than measured dietary concentrations.

Lampe et al. (1999) compared PO intake in ninety-eight men and women using PO and $5 \mathrm{~d}$ diet records with $24 \mathrm{~h}$ urine excretion. This study was carried out in the USA and correlation of urine with PO was 0.20 for daidzein, 0.25 for genistein and 0.25 for total daidzein + genistein. Correlations of urine with $5 \mathrm{~d}$ diet records were 0.34 for daidzein, 0.40 for genistein and 0.25 for total daidzein + genistein. Arai et al. (2000) compared plasma (obtained after overnight fasting) and $24 \mathrm{~h}$ urine excretion with dietary PO intake estimated from $3 \mathrm{~d}$ diet records. The correlation for PO intake $v$. plasma PO was 0.34 for daidzein, and 0.43 for genistein, while for urine $v$. intake the correlation was 0.37 for daidzein and 0.35 for genistein. Frankenfeld et al. (2002) compared the data from their FFQ with genistein and daidzein concentrations in a single plasma sample, collected after an overnight fast. The correlation between the mean of two FFQ values and plasma genistein and daidzein was 0.53 and 0.45 respectively, both of which were significant. Verkasalo et al. (2001) used FFQ and $7 \mathrm{~d}$ food diaries to estimate total dietary PO (genistein + daidzein). Intake data were subsequently compared with PO concentrations in a single plasma sample. Timing of the plasma samples was not specified. The Spearman correlation coefficients for plasma PO $v .7 \mathrm{~d}$ dietary PO were between 0.66 and 0.80 and between 0.24 and 0.74 for FFQ-based estimates. Since no duplicate diet analyses were carried out by these researchers, absolute intakes and their correlation with $24 \mathrm{~h}$ urine excretion and/or plasma PO could not be established.

Analysis of UK vegetarian duplicate diets for PO was carried out by Clarke et al. (2004), but currently there are no corresponding data on urinary excretion or plasma concentrations. Although duplicate diet analysis is the most accurate method for determining dietary intake, 
difficulties with subject compliance restrict the use of this dietary assessment tool. In the current study, PO content of dietary intake for $1 \mathrm{~d}$ was measured. Processing can alter the genistein:daidzein ratio in food (Wang \& Murphy, 1996; Coward et al. 1998), which in turn can affect urinary excretion of genistein and daidzein (Busby et al. 2002).

For dietary PO intakes $<5 \mathrm{mg} / \mathrm{d}$, the database underestimates intake. This suggests that soyabeans or derivatives of soyabean are present in greater amounts in bread or have been added to a wider range of foods than those accounted for in the database.

Total measured PO intake from foods commonly eaten in these diets (such as white, brown and wholemeal breads and rolls) was between 1.18 and $3.41 \mathrm{mg} / \mathrm{d}$. This agrees with the results of Clarke et al. (2004), where analysis of samples from the UK 1998 Total Diet Survey estimated a PO intake of $3 \mathrm{mg} / \mathrm{d}, 75 \%$ of the intake being derived from breads and bakery products.

From Fig. 2, the equation of the line suggests that even if the estimated PO intake was $0.00 \mathrm{mg} / \mathrm{d}$, there would be a minimum background exposure of $1.24 \mathrm{mg} / \mathrm{d}$, presumably from the addition of soyabean flour to bakery products. Volunteer $\mathrm{T}$ who participated in the present study had been diagnosed with wheat intolerance and as a result did not consume wheat-based products. During the $24 \mathrm{~h}$ weighed food recording, the only product consumed that was labelled as containing soyabean flour was 'gluten and wheat-free bread'. Assuming the PO content of this bread was the same as average white bread, dietary intake of PO was estimated at $<0.10 \mathrm{mg} / \mathrm{d}$. In fact, measured dietary PO intake was $1.56 \mathrm{mg}$. Hence, wheatfree breads may contain higher than average levels of soyabean flour or soyabean flour may be added to a variety of foods without appropriate labelling indicating the presence of this agent, or there exist other unidentified sources of PO not related to bakery products (Wang \& Murphy, 1994a).

The range of daidzein excretion in urine was 37 to $92 \%$ of total genistein + daidzein intake; this is probably due to inter-individual variation in metabolism of isoflavones and habitual diet (Kelly et al. 1995; Lu \& Anderson, 1998; Rowland et al. 2000). From Figs. 4 and 5, urine excretion and plasma concentrations of total PO (genistein + daidzein) for $\mathrm{R}$ were greater than the observed trend and urine excretion and plasma concentrations for $\mathrm{Q}$ lower than the observed trend. This indicated that inter-individual variation in metabolism, possibly due to gut microflora, may affect urinary excretion and circulating plasma levels of PO between subjects, but high excretors may also have higher levels of circulating genistein + daidzein. These individual variations in PO metabolism and excretion may be of interest for future studies of dietary influences on health. Methods employed during processing of soyabeans can also influence genistein and daidzein concentrations in foods, as well as the genistein: daidzein ratio (Coward et al. 1998; Slavin et al. 1998). This, in turn, may affect percentage excretion of each analyte, although soyabeans contain higher levels of genistein:daidzein even after processing (Kelly et al. 1995).

Frankenfeld et al. (2002) suggested that isoflavone concentrations from single plasma samples and $24 \mathrm{~h}$ urinary collections would give similar results when compared with dietary intake, but an indication of the exact relationship was not reported in the literature. A biomarker of intake should be present in biological specimens that are easily obtainable, hence ensuring maximum compliance of subjects. In the current study, the relationship between $24 \mathrm{~h}$ urinary PO and timed plasma PO was such that concentrations in a single timed plasma sample accurately reflected both $24 \mathrm{~h}$ excretion and dietary intake of PO. In the present study, urinary excretion of genistein and daidzein represented about $23 \%$ of measured dietary intake. This is in agreement with the results of $\mathrm{Xu}$ et al. (2000), who showed that excretion of genistein + daidzein ranged from 25 to $42 \%$ of intake. Furthermore, genistein concentrations in plasma were higher than daidzein concentrations. This is in agreement with other publications showing higher concentrations of genistein in plasma compared with daidzein (Adlercreutz et al. 1993, 1994; Morton et al. 1994, 2002; Izumi et al. 2000; Djuric et al. 2001; Mitchell et al. 2001; Franke et al. 2002; Frankenfeld et al. 2002; Sanders et al. 2002).

This is the first study to: (1) measure PO content of UK duplicate diets containing a range of PO concentrations; (2) use the information to test a newly constructed database designed for use in assessment of total genistein + daidzein intakes; (3) develop a biomarker of intake by analysis of $24 \mathrm{~h}$ urine collection and timed spot plasma sample for total PO (genistein + daidzein).

Establishing a biomarker of PO intake through the present study means that large epidemiological studies can be carried out and dietary PO intake estimated reasonably accurately from analysis of a $24 \mathrm{~h}$ urine collection or timed plasma sample. Furthermore, it eliminates the need for food diaries and corresponding time spent analysing records to estimate PO intake for large studies.

From the results obtained it can be shown that there is a good correlation ( $r$ 0.98) between estimated PO intake using the database with measured PO intake from duplicate diet analysis. In addition, the database predicts $125 \%$ of actual intake and predicted PO intake depends on amount of intake (low, moderate or high). Urine excretion (24h) of genistein + daidzein (using PABA to check completeness) correlates $(r 0.97)$ with measured dietary PO intake, while timed plasma PO concentrations (genistein + daidzein) correlate $(r$ 0.92) with measured dietary PO intake and $24 \mathrm{~h}$ urine collections. The results also provide evidence of inter-individual variation in PO metabolism.

\section{Acknowledgement}

This study was supported by funds from the Anonymous Trust, University of Dundee.

\section{References}

Adlercreutz H, Fotsis T, Watanabe S, Lampe J, Wahala K, Makela T \& Hase T (1994) Determination of lignans and isoflavonoids in plasma by isotope dilution gas chromatography-mass spectrometry. Cancer Detect Prev 18, 259-271.

Adlercreutz H, Markkanen H \& Watanabe S (1993) Plasma concentrations of phyto-oestrogens in Japanese men. Lancet 342, 1209-1210. 
Arai Y, Uehara M, Sato Y, Kimira M, Eboshida A, Adlercreutz H \& Watanabe S (2000) Comparison of isoflavones among dietary intake, plasma concentration and urinary excretion for accurate estimation of phyto-oestrogen intake. J Epidemiol 10, 127-135.

Bingham SA \& Cummings JH (1983) The use of 4-aminobenzoic acid as a marker to validate the completeness of $24 \mathrm{~h}$ urine collections in man. Clin Sci 64, 629-635.

Bingham SA, Nelson M, Paul AA, Haraldsdottir J, Loken EB \& Van Stavern WA (1988) Methods for data collection at an individual level. In Manual On Methodology for Food Consumption Studies, pp. 54-320 [ME Cameron and WA Van Stavern, editors]. Oxford: Oxford University Press.

Busby M, Jeffcoat AR, Bloedon LT, et al. (2002) Clinical characteristics and pharmacokinetics of purified soy isoflavones: single-dose administration to healthy men. Am J Clin Nutr 75, 126-136.

Clarke DB, Barnes KA, Castle L, Rose M, Wilson LA, Baxter MJ, Price KR \& DuPont MS (2004) Levels of phytoestrogens, inorganic trace elements, natural toxicants and nitrate in vegetarian duplicate diets. J Agric Food Chem (In the Press).

Clarke DB, Lloyd AS, Oldfield MF, Botting NP, Needs PW \& Wiseman H (2002) Measurement of the intact sulfate and glucuronide conjugates of phytoestrogens in human urine using direct injection HPLC and electrospray tandem mass spectrometry with $\left[{ }^{13} \mathrm{C}_{3}\right]$ isoflavone internal standards. Anal Chem 309, 158-172.

Coward L, Barnes NC, Setchell KDR \& Barnes S (1993) Genistein, daidzein and their beta-glycoside conjugates: antitumour isoflavones in soybean foods from American and Asian Diets. J Agric Food Chem 41, 1961-1967.

Coward L, Smith M, Kirk M \& Barnes S (1998) Chemical modification of isoflavones in soyfoods during cooking and processing. Am J Clin Nutr 68, 1486S-1491S.

Djuric Z, Chen G, Doerge DR, Heilbrun LK \& Kucuk O (2001) Effect of soy isoflavone supplementation on markers of oxidative stress in men and women. Cancer Lett 172, 1-6.

Franke AA, Custer LJ, Wilkens LR, Le Marchand L, Nomura AMY, Goodman MT \& Kolonel LN (2002) Liquid chromatographic-photodiode array mass spectrometric analysis of dietary phyto-oestrogens from human urine and blood. $J$ Chromatogr B 777, 45-59.

Frankenfeld CL, Patterson RE, Kalhorn TF, Skor HE, Howald WN \& Lampe JW (2002) Validation of a soy food frequency questionnaire with plasma concentrations of isoflavones in US adults. $J$ Am Diet Assoc 102, 1407-1413.

Grace PB, Taylor JI, Botting NP, Fryatt T, Oldfield MF, Al-Maharik N \& Bingham SA (2003a) Quantification of isoflavones and lignans in serum using isotope dilution liquid chromatography/tandem mass spectrometry. Rapid Commun Mass Spectrom 17, 1350-1357.

Grace PB, Taylor JI, Botting NP, Fryatt T, Oldfield MF \& Bingham SA (2003b) Quantification of isoflavones and lignans in urine using gas chromatography/mass spectrometry. Anal Biochem 315, 114-121.

Habito RC, Montalto J, Leslie E \& Ball MJ (2000) Effects of replacing meat with soyabean in the diet on sex hormone concentrations in healthy adult males. $B r J$ Nutr 84, $557-563$.

Irvine C, Shand N, Fitzpatrick M \& Alexander S (1998) Daily intake and urinary excretion of genistein and daidzein by infants fed soy- or dairy-based infant formulas. Am J Clin Nutr 68, 1462S-1465S.

Izumi T, Piskula MK, Osawa S, Obata A, Tobe K, Saito M, Katao S, Kunota Y \& Kikuchi M (2000) Soy isoflavone aglycones are absorbed faster and in higher amounts than their glucosides in humans. J Nutr 130, 1695-1699.
Jones A, Price K \& Fenwick G (1989) Development and application of a high-performance liquid chromatographic method for the analysis of phytoestrogens. J Sci Food Agric 46, $357-364$.

Kelly GE, Joannou GE, Reeder AY, Nelson C \& Waring MA (1995) The variable metabolic response to dietary isoflavones in humans. Proc Soc Exp Biol Med 208, 40-43.

Kirk P, Patterson RE \& Lampe J (1999) Development of a soy food frequency questionnaire to estimate isoflavone consumption in US adults. $J$ Am Diet Assoc 99, 558-563.

Lampe J, Gustafson D, Hutchins A, Martini MC, Li S, Wahala K, Grandits GA, Potter JD \& Slavin JL (1999) Urinary isoflavonoid and lignan excretion on a Western diet: relation to soy, vegetable and fruit intake. Cancer Epidemiol Biomarkers Prev 8, 699-707.

Liggins J, Bluck LJC, Coward WA \& Bingham SA (1998) Extraction and quantification of daidzein and genistein in food. Anal Biochem 264, 1-7.

Liggins J, Mulligan A, Runswick S \& Bingham SA (2002) Daidzein and genistein content of cereals. Eur J Clin Nutr 56, 961-966.

Lu L \& Anderson K (1998) Sex and long-term soy diets affects the metabolism and excretion of soy isoflavones in humans. Am J Clin Nutr 68, 1500S-1504S.

Mitchell JH, Cawood E, Kinniburgh D, Provan A, Collins AR \& Irvine DS (2001) Effect of a phyto-oestrogen food supplement on reproductive health in normal males. Clin Sci 100, 613-618.

Morton MS, Arisaka O, Miyake N, Morgan LD \& Evans BAJ (2002) Phytoestrogen concentrations in serum from Japanese men and women over forty years of age. J Nutr 132, 3168-3171.

Morton MS, Wilcox G, Wahlqvist ML \& Griffiths K (1994) Determination of lignans and isoflavonoids in human female plasma following dietary supplementation. $J$ Endocrinol 142, 251-259.

Pumford SL, Morton MS, Turkes A \& Griffiths K (2002) Determination of the isoflavonoids genistein and daidzein in biological samples by gas chromatography-mass spectrometry. Ann Clin Biochem 39, 281-292.

Reinli K \& Block G (1996) Phytoestrogen content of foods A compendium of literature values. Nutr Cancer 26, 123-148.

Richelle M, Pridmore-Merten S, Bodenstab S, Enslen M \& Offord EA (2002) Hydrolysis of isoflavone glycosides to aglycones by $\beta$-glycosidase does not alter plasma and urine isoflavone pharmacokinetics in postmenopausal women. $J$ Nutr 132, 2587-2592.

Ritchie MR, Morton MS, Bolton-Smith C \& Cummings JH (2001) Correlation between dietary and urinary phyto-oestrogens (genistein and daidzein) in healthy adults. Proc Nut Soc 60, $136 \mathrm{~A}$.

Rowland I, Wiseman H, Sanders B, Adlercreutz H \& Bowey E (2000) Interindividual variation in metabolism of soy isoflavones and lignans: influence of habitual diet on equal production by the gut microflora. Nutr Cancer 36, 27-32.

Sanders TAB, Dean TS, Grainger D, Miller GJ \& Wiseman H (2002) Moderate intakes of intact soy protein rich in isoflavones compared with ethanol-extracted soy protein increase HDL but do not influence transforming growth factor $\beta_{1}$ concentrations and haemostatic risk factors for coronary heart disease in healthy subjects. Am J Clin Nutr $\mathbf{7 6}$, 373-377.

Setchell KDR, Brown NM, Desai P, Zimmer-Nechmias L, Wolfe BE, Brashear WT, Kirschner AS, Cassidy A \& Heubi JE (2001) Bioavailability of pure isoflavones in healthy humans and analysis of commercial soy isoflavone supplements. J Nutr 131, $1362 \mathrm{~S}-1375 \mathrm{~S}$. 
Slavin J, Karr S, Hutchins A \& Lampe J (1998) Influence of soybean processing, habitual diet, soy dose on urinary isoflavonoid excretion. Am J Clin Nutr 68, 1492S-1495S.

Tsunoda N, Pomery S \& Nestel P (2002) Absorption in humans of isoflavones from soy and red clover is similar. J Nutr 132, 2199-2201.

Uehara M, Lapcik O, Hampl R, Al-Maharik N, Makela T, Wahala K, Mikola H \& Adlercreutz H (2000) Rapid analysis of phytooestrogens in human urine by time-resolved fluorimmunoassay. J Steroid Biochem Mol Biol 72, 273-282.

US Department of Agriculture-Iowa State University (1999). Data-base on the Isoflavone Content of Foods. http://www. nal.usda.gov/fnic/foodcomp/Data/isoflav/isofalv.html

Verkasalo PK, Appleby PN, Allen NE, Davey G, Adlercreutz H \& Key TJ (2001) Soy intake and plasma concentrations of daidzein and genistein: validity of dietary assessment among eighty British women (Oxford arm of the European Prospective Investigation into Cancer and Nutrition). Br J Nutr 86, 415-421.

Wang GW, Kuan SS, Francis OJ, Ware GM \& Carman AS (1990) A simplified HPLC method for the determination of phyto-oestrogens in soybean and its processed products. J Agric Food Chem 38, 185-190.
Wang H \& Murphy PA (1994a) Isoflavone content in commercial soybean foods. J Agric Food Chem 42, 1666-1673.

Wang H \& Murphy PA (1994b) Isoflavone composition of American and Japanese soybeans in Iowa: Effects of variety, crop year, and location. J Agric Food Chem 42, $1674-1677$.

Wang H \& Murphy PA (1996) Mass balance of isoflavones during soybean processing. J Agric Food Chem 44, $2377-2383$.

Wild CP, Andersson C, O'Brien NM, Wilson L \& Woods JA (2001) A critical evaluation of the application of biomarkers in epidemiologial studies on diet and health. Br J Nutr 86, S37-S53.

Xu X, Wang H, Murphy PA \& Hendrich S (2000) Neither background diet nor type of soy food affects short term isoflavone bioavailability in women. $J$ Nutr 130, 798-801.

Yamamoto S, Sobue T, Sasaki S, et al. (2001) Validity and reproducibilty of a self-administered food-frequency questionnaire to assess isoflavone intake in a Japanese population in comparison with dietary records and blood and urine isoflavones. J Nutr 131, 2741-2747. 